\title{
The Comparative Impacts of Social Justice Educational Methods on Political Participation, Civic Engagement, and Multicultural
}

\section{Activism}

\author{
Amy Krings \\ Loyola University Chicago, akrings@luc.edu \\ Elizabeth A. Austic \\ The University Of Michigan \\ Lorraine M. Gutierrez \\ The University Of Michigan \\ Kaleigh E. Dirksen \\ Fqlilowhthis and Ordditiphag _works at: https://ecommons.luc.edu/socialwork_facpubs \\ Part of the Social Work Commons \\ Author Manuscript \\ This is a pre-publication author manuscript of the final, published article.
}

\section{Recommended Citation}

Krings, Amy; Austic, Elizabeth A.; Gutierrez, Lorraine M.; and Dirksen, Kaleigh E.. The Comparative Impacts of Social Justice Educational Methods on Political Participation, Civic Engagement, and Multicultural Activism. Equity \& Excellence in Education, 48, 3: 403-417, 2015. Retrieved from Loyola eCommons, Social Work: School of Social Work Faculty Publications and Other Works, http://dx.doi.org/10.1080/ 10665684.2015.1057087

This Article is brought to you for free and open access by the Faculty Publications and Other Works by Department at Loyola eCommons. It has been accepted for inclusion in Social Work: School of Social Work Faculty Publications and Other Works by an authorized administrator of Loyola eCommons. For more information, please contact ecommons@luc.edu.

\section{c) (i) $\Theta($}

This work is licensed under a Creative Commons Attribution-Noncommercial-No Derivative Works 3.0 License. Author Posting (c) University of Massachusetts Amherst College of Education, 2015. 


\section{The Comparative Impacts of Social Justice Educational Methods on Political Participation, Civic Engagement, and Multicultural Activism}

Amy Krings, Elizabeth A. Austic, Lorraine M. Gutie' rrez, and Kaleigh E. Dirksen

This cross-sectional, repeated measures, quasi-experimental study evaluates changes in college students' commitment toward, and confidence in, political participation, civic engagement, and multi- cultural activism. Our sample $(n=653)$ consisted of college students in a Midwestern university who participated in one of three social justice education course types (service learning, intergroup dialogue, or lecture-based diversity classes) or in an "introduction to psychology" course (the non-intervention group). After completion of a social justice education course, students reported an increase in political participation and multicultural activism, whereas students enrolled in the non-intervention group reported no changes in these measures. Service learning course participants started and ended their course with the highest reported levels of political participation, civic engagement, and multicultural activism but did not demonstrate an increase in any of the three outcomes. Intergroup dialogue participants demonstrated increases in all three outcomes, while participants of lecture-based classes focusing on social justice issues demonstrated increases in political participation and multicultural activism, but not civic engagement. Our findings suggest that participation in social justice education courses is associated with increases in political participation and multicultural activism.

One goal of social justice education is to advance the full and equal participation of all groups in society (Adams, Bell, \& Griffin, 2007). To achieve this end, social justice educators aim to provide students with the skills and confidence necessary to engage in political participation, civic engagement, and multicultural activism, as well as other attitude and behavioral changes. Social justice education course content is typically designed to develop students' awareness of multicultural group dynamics, as well as their tools for critical analysis, social change, and personal reflection (Hackman, 2005). Social justice courses are organized around increasing students' social awareness and orientation toward responsible social action; thus, they hold the potential to answer the call for colleges and universities to develop committed, engaged, and socially responsible citizens who are prepared to participate in public life. This study assesses the degree to which social justice courses prepared students at a Midwestern university for community and civic engagement.

Social justice education courses can employ different pedagogies and methods. For example, service learning courses require community participation to demonstrate and reinforce course content. Within intergroup dialogues, small facilitated groups composed of students from two conflicting social identity groups come together to reflect on social inequality, the social forces that shape their identities, and possibilities for collaborative social action (Gurin, Meier, \& Gurin- Sands, 2013). Although lacking an experiential component, traditional lecture and discussion classes can be social justice courses when they include content that emphasizes social issues while introducing students to relevant forms of action. 
Although there is variation in social justice course types, previous empirical work tends to study the outcomes of only one pedagogical type, such as service learning or intergroup dialogues (e.g., Conway, Amel, \& Gerwien, 2009; Gurin, Nagda, \& Zún i iga, 2013). Meta analyses have studied the potential effects of more than one type of social justice education or related experience, yet few have looked systematically at the impact of different social justice education pedagogies (Bowman, 2011; Manning \& Edwards, 2014). Our research design addressed these limitations by including three distinct social justice course types, a comparison group, and preand posttests to measure change between the beginning and end of each semester-long course.

\section{AS SES SING THE IMP ACT OF S OCIAL JUS TICE COURSES}

In the following section, we discuss a range of empirical studies that assessed the effects of social justice courses, particularly those that evaluated any of the three outcomes measured in our study: political participation, civic engagement, and multicultural activism. Although previous literature on social justice education tends to evaluate each course type independently, we highlight studies that compared outcomes relating to two or more social justice pedagogies.

Service Learning

A major aim of service learning courses is to encourage students to develop a sense of civic or community responsibility (Weber, Weber, \& Young, 2010), advancing students' notion of social change from a mindset of charity to the promotion of social justice (Kendall, 1990). The mechanisms of change are collaborative community-based learning that intends to be responsive to local needs and reflective analysis (Boyle-Baise, 2002; Einfeld \& Collins, 2008). Further, preliminary evidence suggests that service learning is more effective than traditional, lecturebased classes because it provides a forum for students to integrate class content with their service activities and personal experiences (Markus, Howard, \& King, 1993).

Previous work evaluating service learning course outcomes suggests that service learning can be an effective tool for developing multicultural competence, personal development, and linking the college experience to the community (Boyle-Baise, 2002; Einfeld \& Collins, 2008). Service learning is also associated with an increase in civic responsibility and commitment to social action (Einfeld \& Collins, 2008; Monard-Weissman, 2003). Using a sample of 1,500 students from 20 universities, Eyler, Giles, and Braxton (1997) found that service learning participants were more likely to endorse systematic approaches to social problems, endorse social justice as a priority for society, and empathize with others, as compared with non-service learning participants. They note that students who volunteered to take service learning courses held many of these same beliefs and perspectives prior to engaging in service, raising the concern of selfselection bias.

IMPACTS OF SOCIAL JUSTICE EDUCATIONAL METHODS 405 
Conway, Amel, and Gerwein (2009), in a meta-analysis of samples from 103 studies, found evidence that service learning programs were positively associated with students' academic and social outcomes, particularly when programs included structured reflection.

Intergroup Dialogue

Intergroup dialogue courses are comprised of students representing two or more identity groups with a history of conflict (for example, on the basis of race, gender, religion, or political orientation) (Gurin-Sands, Gurin, Nagda, \& Osuna, 2012; Zuniga, Lopez, \& Ford, 2012). These two identity groups then engage in facilitated and sustained critical conversations and, ultimately, collaborate as allies to work toward social justice. Intergroup dialogue is unique in that it provides participants more sustained and structured opportunities to reflect upon their identity and role as a change agent than typical lecture-based courses (Alimo, 2012; Gurin, Nagda, \& Zún iga, 2013).

A Multi-University Intergroup Dialogue Research Project implemented random-assignment field experiments at nine higher education institutions to evaluate the efficacy of intergroup dialogues focused on race or gender (Nagda, Gurin, Sorensen, Gurin-Sands, \& Osuna, 2009). The study found that students who participated in intergroup dialogues that were focused on race were better able to critique inequality, when compared to their counterparts in control and comparison groups. The race dialogue participants also demonstrated a higher commitment to post-college action to promote social justice, influence the political structure, and work to achieve greater gender quality. Additional evaluations of intergroup dialogues using pre- and posttest research designs have found increases in students' action orientations away from individual blaming and toward institutional and social targets (Nagda, Gurin, \& Lopez, 2003), as well as increases in motivation for - and confidence in - engaging in personal and social action to reduce prejudice and promote diversity (Nagda, Kim, \& Truelove, 2004).

\section{Lecture-Based Divers ity Course}

Many colleges and universities in the United States include a mandatory diversity course for their students. These courses typically include content about race, gender, social class, disability, and other social identities, and are designed to promote cultural pluralism in a diverse world. These policies are based on the assumptions that these courses can increase cultural knowledge and awareness, can contribute to attitude and behavioral change, and may support greater political participation, civic engagement, or multicultural activism (Cole, Case, Rios, \& Curtain, 2011; Dewey, 1939; Freire, 1970). Some suggest that although lectures, class presentations, and research projects may cultivate new knowledge and awareness, this traditional pedagogy is likely to be less rigorous than participatory methods, such as service learning or dialogue, and may therefore be less likely to facilitate behavioral change in individuals (Mayhew \& Fernandez, 2007). Sleeter argues that multicultural education was originally viewed as an advocacy tool, although today it is more commonly associated with cross-cultural awareness that is at times devoid of critical analysis (Sleeter, 1996). 
Preliminary evidence suggests that lecture and discussion-based social justice courses, sometimes called diversity courses, teach students to negotiate and communicate across groups and result in an increased commitment to social action (Laird, Engberg, \& Hurtado, 2005). Diversity classes aimed at reducing student bias also are associated with increases in participants' awareness of racism and white privilege (Case, 2007). Although lecture-based courses are less experiential than service learning or intergroup dialogues, these findings suggest that they can increase student commitment to social justice outcomes. This article examines the effectiveness of social justice education courses in affecting student commitment toward, and confidence in, political participation, civic engagement, and multicultural activism.

\section{METHODS}

Our study is part of a comprehensive, multi-year project that includes a cross-sectional, repeated measures, quasi-experimental research design with an ethnically diverse group of students from a large Midwestern university $(N=803)$. Our research goal was to evaluate the role that higher education can play in preparing students for active participation in an increasingly multicultural world. Each participant completed separate multi-page survey packets at pretest, posttest, and follow-up stages. The survey packets at all three stages of the study included both quantitative and qualitative measurements of the following items: demographic information; motivations for taking the course; previous participation in other social justice courses; knowledge of social inequality; attitudes toward different racial and ethnic groups; attitudes towards gender equality; and interest in collective civic and political action.

Given the breadth of the survey, our study focuses on the impact of a social justice course on three outcome measures that are typically associated with collective action: political participation, civic engagement, and multicultural activism. Future research will examine relationships between community engagement and social identities including race, gender, class, and religious affiliation.

\section{Sample}

All students enrolled in four different undergraduate courses over a three-year period were invited to participate in the study. The three-year time frame for data collection was selected to generate a large enough sample to obtain sufficient statistical power for more complex analyses. Eight hundred and three respondents completed a pre- or posttest survey given on the first and last days of class during the three-year study. Six hundred and ninety-four (694, 86.3\%) respondents completed both the pre- and the posttest surveys. Six hundred and fifty $(650,80.9 \%)$ of these respondents answered questions about civic engagement, volunteering, and multicultural action at both pre- and posttest, and were included in the subsample for analysis. Three additional respondents $(0.4 \%)$ answered questions about at least two of these three topics on their pre- and posttests, and were included in the final subsample for analysis $(n=653,81.3 \%)$. Results were nearly identical when we reran our analyses excluding these three $(0.4 \%)$ respondents with partially missing data. Forty-one $(41,5.1 \%)$ respondents who completed preand posttests, but who answered questions about only one, or less than one, of these three topics 
on their pre- and posttests were excluded from analysis. The final retention rate for the project was $74 \%$ for Year $1 ; 77 \%$ for Year 2; and $73 \%$ for Year 3.

Students were asked to self-report their gender, racial group, social class, age, and year in the university (see Table 1). Sixty-one percent were women. Fifty percent were Caucasian, 19.9\% were African American, 18.7\% were Asian, and 11.4\% identified as "other race or ethnicity" groups. Thirty-three percent identified as being in a higher socioeconomic class, $52.5 \%$ as being in the middle class, and $14.6 \%$ as being in a lower class. The average age of participants was 20 years, and their most frequently reported year in school was sophomore. Compared with the original sample $(N=803)$, the subsample ( $n=653,81.3 \%$ ) for analysis had a smaller proportion of respondents from the lecture-based diversity course and a smaller proportion of respondents who identified as African American or "other," but did not differ from the original sample by gender, age, socioeconomic class, or by years in college.

Course Selection

We selected three social justice education courses that used different pedagogies that could be compared and contrasted in respect to outcomes. Each course met for one semester, offered three-four credit units, and met for three hours per week. These particular courses were selected because they were all undergraduate level, offered social science credit, and enrolled at least 100 students annually. These similarities allowed us to focus on many different outcomes that may be related to pedagogy rather than approach or discipline. All respondents $(n=653)$ participated in one of three social justice education courses: service learning $(n=118)$, intergroup dialogue $(n=$ $160)$, or a lecture-based diversity course focusing on social justice topics $(n=233)$. We also analyzed a non-treatment comparison group (an Introduction to Psychology course, $n=142$ ). We describe each of these courses briefly below.

Service Learning

The courses in this category were comprised of three linked seminars that were cross-listed in the Departments of Psychology and American Culture. Lectures, discussions, and readings had a social justice focus and addressed topics such as structural inequality, privilege and oppression, community-based action, and empowerment theory and practice. Students were required to participate in a service learning internship during the course and spent two hours per week at a community-based organization for a total of 24 hours over the semester. The community internships took place at community-based organizations, such as a Head Start early childhood education center and after school programs in low-income, racially and ethnically diverse, urban neighborhoods. Course goals included promoting an understanding of the basic concepts of community psychology and multiculturalism; promoting well being and empowerment; promoting the development of specific techniques to understand how these concepts can be incorporated into community-based, empowering programs; and learning about specific community programs through participation in predominately African American and Latino communities. 
Inte rgroup Dialogue

The intergroup dialogue model was developed by the Program on Intergroup Relations at the University of Michigan and has been adopted by numerous colleges and universities as a way to facilitate critical conversations about social justice issues related to social identities, privilege, inequality, and conflict (Zuniga, Lopez, \& Ford, 2012). The intergroup dialogue courses evaluated in this study were listed in the Department of Psychology. Each dialogue had two trained peer undergraduate facilitators who each represented at least one the primary identities that were the focus of the dialogue (e.g., one white woman and one man of color co-facilitating a race-ethnicity dialogue; one gay man and one heterosexual woman co-facilitating a gender dialogue). Each of these peer facilitators previously participated in an intergroup dialogue course and training to become a facilitator. Likewise, each intergroup dialogue course had fairly equal numbers of the identity groups that were the focus of the dialogue (e.g., an equal number of women and men in a gender dialogue). Participants were challenged to take a critical perspective when examining issues of conflict, power, privilege, and oppression (Zuniga, Lopez, \& Ford, 2012), and they were encouraged to engage in collaborative action to challenge oppressive social structures.

\section{Lecture-Based Diversity Course}

Many colleges and universities require students to attend a "diversity course"-typically focused on contemporary cultures. The course evaluated in this category was required of Residence Hall Assistants prior to beginning their work for the year and was listed in the Department of Psychology. Content included college student development and identity development theory, interpersonal and intergroup communication, conflict management, and the role of power and privilege in intergroup relations. By the end of the course, participants were expected to have a better understanding of interpersonal and intergroup conflict, problem solving, and the ability to educate others and to organize them to engage in collaborative action.

Introduction to Psychology

This large lecture-based course provided students with a broad introduction to scholarship and research methodologies in the field of psychology. The format of the course was a large lecture with multiple discussion sections. Students in our comparison group were recruited from this course's subject pool. The course did not include an experiential component, nor a specific focus relating to any of our three outcomes. Thus, this course provided a comparison group with similar demographic characteristics that was not exposed to the social justice course intervention. This comparison group allowed us to reduce the possibility that changes in our outcome measures were the result of the college experience for these cohorts.

\section{Hypotheses}

The central question driving this study is: Do social justice education courses influence students' reported attitudes about political participation, civic engagement, and multicultural activism? To 
address this question, this study begins by testing the hypothesis that all three social justice pedagogical approaches (service learning, intergroup dialogue, and lecture) would be associated with students reporting an increase in their confidence in, and the perceived importance of, engaging in political participation, civic engagement, and multicultural activism.

Our second hypothesis was that courses with an experiential component-service learning or intergroup dialogues - would have a greater impact on students' reported outcomes than the lecture-based courses. As suggested by previous research, we predicted that this experiential process of learning would result in greater change than courses that were restricted to lectures, class presentations, and research projects. Our prediction was based on the notion that students in service learning and intergroup dialogue courses are likely to engage in what Paolo Friere called praxis - the ongoing interaction between reflection and actions that promote individual and community change (Adams, Bell, \& Griffin, 1997; Freire, 1970; Mayhew \& Fernandez, 2007; Nagda, Gurin, \& Lopez, 2003).

Me a sures

We conceptualize social justice learning as the development of awareness, knowledge, and skills centering on the relationships among agency, society, power, and inequality, with particular attention to race and gender. This conceptualization is consistent with those of Pedersen (1988), Shor (1992), and Mayhew and Fernandez (2007). However, for the purposes of this study, we selected three dependent variables: political participation, civic engagement, and multicultural activism because we wanted to shed light on the degree to which social justice education prepares participants to engage in social justice-oriented collective action.

Nagda, Gurin, and Lopez (2003) and the Cooperative Educational Research Program (CERP) have described the development of the selected measures in detail in previous publications (see, http:/www.heri.ucla.edu/researchersToolsCodebooks.php). These measures have demonstrated high validity and reliability across a number of studies and college campuses (e.g., Gurin, Nagda, \& Zu'n iga, 2013; Higher Education Research Institute, 1994). To operationalize our three dependent variables, we selected one of these survey items to measure political participation and used factor analysis to develop scales to measure civic engagement and multicultural activism. Each of the selected survey items asked how much participants agreed or disagreed that a specific action was: (1) important to the respondent (Importance), (2) a life priority for the respondent (Life Priority), or (3) an action the respondent felt confident taking (Confidence).

The survey item used to assess political participation asked how important "influencing the political structure" was to participants. This item was taken from the Higher Education Research Institute Freshman Survey (1994) "life goal" measures. Participants could select a response from 1 (not very important) to 4 (very important).

The civic engagement scale was generated from items developed by Gurin, Nagda, and Zu' ñ iga, (2013) for research on the outcomes of intergroup dialogues. This scale was made up of four items with an alpha of .815 at both pre- and posttest. Individual items asked respondents to rate 
the importance and their confidence in "Join(ing) an organization that takes action towards justice" and the importance and their confidence in "Gett(ing) together with others to challenge an unjust practice."

The multicultural activism scale was comprised of five items from two sections of the questionnaire. This scale had an alpha coefficient of .737 at the pretest and of .704 at the posttest. One of the individual items asked respondents to indicate how important, on a scale of 1 (not very important) to 4 (very important), "Working toward equal opportunity for all US citizens" was to them. This item was taken from the Higher Education Research Institute Freshman Survey "life goal" measures (1994). The remaining items were from the Gurin, Nagda, and Zu' ñ iga (2013) measures for research on the outcomes of intergroup dialogues. The individual items asked respondents to rate the importance and their confidence in "Reinforc(ing) others for behaviors that support cultural diversity" and the importance and their confidence in "Call(ing), writ(ing) or in some way protest(ing) when a book, newspaper, television show, or some branch of media perpetuates or reinforces a bias or prejudice."

Scores on the individual civic engagement and multicultural activism measures were averaged to maintain a scale of 1-4. As long as a respondent answered at least two of the questions relating to civic engagement and multicultural activism, their answers were included in the analysis, allowing us to retain a larger sample size. Individuals who did not meet these minimum criteria were excluded from the analysis.

Analys is

Using multivariate repeated measurement ANOVA, we conducted three sets of analyses comparing the non-intervention and intervention groups' (service learning, intergroup dialogue, and lecture discussion) pre- and posttest responses on three dependent variables (political participation, civic engagement, and multicultural activism). Race, gender, and socioeconomic status were held constant for all analyses.

Analysis A tested for differences between the non-intervention and intervention groups for the three dependent variables combined (i.e., for political participation, civic engagement, and multicultural activism combined). Analysis B tested for differences between the non-intervention and intervention groups for each of the three dependent variables (i.e., for political participation, civic engagement, and multicultural activism tested separately). Analysis $\mathrm{C}$ tested for differences between the non-intervention group and each of the three social justice course conditions for each of the three dependent variables. For example, for analysis C: one ANOVA model tested for differences in political participation between the comparison group and the service learning group, while another ANOVA model tested for differences in civic engagement between the comparison group and the intergroup dialogue group.

\section{RESULTS}


In support of the first hypothesis, results from Analysis A confirmed there was a significant difference between the intervention and non-intervention groups' reported commitment to political participation, civic engagement, and multicultural activism, $F(1,622)=13.79, p<.001$ (time by group: $F(1,622)=5.05, p<.05)$. The three tests in Analysis B confirmed significant differences in political participation, $F(1,622)=16.38, p<.001$, civic engagement, $F(1,622)=$ $3.19, p<.05$, and multicultural activism, $F(1,622)=8.99, p<.001$ (Table 2 ). The nonintervention group showed no significant change in the three dependent variables while the intervention groups showed significant change in political participation $(p<.05)$ and multicultural activism $(p<.05)$ and a trend in the predicted direction for civic engagement $(p=$ $.16)$.

Results from the three tests in Analysis C did not support our second hypothesis that the pre- and posttest change in the three dependent variables would be most pronounced in the experiential intervention groups (service learning and intergroup dialogue) (Table 3). Notably, no significant changes in the service learning group, relative to the non-intervention group, across the three dependent variables was observed. As shown in Figures 1-3, this may be due to service learning students starting their courses with higher mean levels of commitment to political participation, civic engagement, and multicultural activism than students in the intergroup dialogue, lecturebased diversity course, or comparison group conditions. The tests in Analysis $\mathrm{C}$ confirmed significant change in the three dependent variables for intergroup dialogue participants $(p<.05)$, and significant change in political participation $(p<.05)$ and multicultural activism $(p<.01)$, and a trend in the predicted direction for civic engagement for the lecture/discussion group $(p=$ $.12)$.

Figures 1-3 show pre- and posttest mean scores for political participation, civic engagement, and multicultural activism (respectively) for the non-intervention group and all three of the social justice course groups. Figure 1 shows a significant positive change in mean political participation for intergroup dialogue and the lecture-based diversity course participants, relative to the nonintervention group participants. Figure 2 shows a significant positive change in mean civic engagement for intergroup dialogue participants, relative to the non-intervention group participants. Figure 3 shows significant positive changes in mean multicultural activism for intergroup dialogue and lecture/discussion participants, relative to the non-intervention group participants.

\section{DIS CUS S ION}

In support of our first hypothesis, our results indicate that participation in social justice education courses is associated with increases in both student confidence in and commitment toward political participation, civic engagement, and multicultural activism, as compared with the nontreatment class. We did not find an association between the non-intervention course and our measurable outcomes, suggesting that simply being in college for a semester is not a sufficient mechanism to shift social justice orientations or behaviors. 
We found partial support for our second hypothesis that the greatest increases in political participation, civic engagement, and multicultural activism would be observed in the more experiential social justice education courses (service learning and intergroup dialogue) as compared with lecture-based social justice education course. Participation in an intergroup dialogue course was associated with increases in political participation, civic engagement, and multicultural activism $(p<.05)$. Participation in an experiential service learning course, however, was not associated with any change in these measures. Participation in the lecture-based diversity course focusing on social justice issues was associated with significant positive change in political participation $(p<.05)$ and multicultural activism $(p<.01)$, and a trend level positive change in civic engagement $(p=.12)$. Our findings contrast with those of Mayhew and Fernandez (2007), who found that "over and above course content, student learning about social justice-related issues can be enhanced by providing structured opportunities for them to reflect on and engage in discussions related to diversity in and outside of the classroom" (p. 75).

When interpreting the findings of our second hypothesis, it is important to take responses to baseline measures on the pretest into account. On their pretests, service learning course participants reported the highest levels of confidence in and commitment toward political participation, civic engagement, and multicultural activism of any of the four groups. Intergroup dialogue participants reported higher levels of political participation and multicultural activism at baseline, relative to the lecture-based diversity course and comparison group condition (Introduction to Psychology) students. On the posttest administered at the end of the semester, service learning course participants reported equally high levels of political participation, civic engagement, and multicultural activism. Thus, there is evidence of a self-selection into both of the experiential courses. Future research could address this challenge to interpretation by implementing random assignment. We acknowledge, however, that this practice is particularly difficult to implement in educational field research.

This study represents one of the first to evaluate the effects of social justice education courses at this scale, thus it has several strengths. The sample is ethnically diverse and large enough to examine subgroup differences. Nonetheless, the study design also constrains interpretations; first, we cannot generalize to other college student populations since the sample was from one region and included students attending one large university. Other factors may have changed among the participants over the three years of the study, including the political climate, the teachers and facilitators of each course, the time of day the course was offered, and the time of year the course was offered (fall, winter, or spring/summer). Thus, we cannot rule out the possibility that, in addition to course methodology, these and other unaccounted for factors contributed to changes in political participation, civic engagement, and multicultural activism.

As colleges and universities increasingly support educational programs designed to prepare their graduates to live and work in a diverse democracy, it is necessary to measure the efficacy of social justice course types. Our findings suggest that social justice courses are positively associated with students' confidence in and willingness to participate in public life through political participation, civic engagement, and multicultural activism. Our findings also suggest that course types vary in the extent to which they are associated with these outcomes, although 
self-selection into some classes may play a role. We hope that this study will motivate future research about social justice education and its impact on students. 
FIGURE 1 Mean Political Participation by Course Type. 
FIGURE 2 Mean Civic Engagement by Course Type. 
FIGURE 3 Mean Multicultural Activism by Course Type. 


\section{REFERENCES}

Adams, M., Bell L. A., \& Griffin P. (Eds.). (1997). Teaching for diversity and social justice: A sourcebook. New York, NY: Routledge.

Adams, M., Bell, L. A., \& Griffin, P. (2007). Teaching for diversity and social justice (2nd ed.). New York, NY: Routledge. Alimo, C. J. (2012). From dialogue to action: The impact of crossrace intergroup dialogue on the development of white

college students as racial allies. Equity \& Excellence in Education, 45(1), 36-59.

Bowman, N. A. (2011). Promoting participation in a diverse democracy: A meta-analysis of college diversity experiences and civic engagement. Review of Educational Research, 81(1), 2968.

Boyle-Baise, M. (2002). Multicultural service learning: Educating teachers in diverse communities. New York, NY:

Teachers College Press.

Case, K. A. (2007). Raising white privilege awareness and reducing racial prejudice: Assessing diversity course effectiveness. Teaching of Psychology, 34(4), 231-235.

Cole, E., Case, K., Rios, D., \& Curtin, N. (2011). Understanding what students bring to the classroom: Moderators of the

effects of diversity courses on student attitudes. Cultural Diversity and Ethnic Minority Psychology, 17(4), 397-405. Conway, J. M., Amel, E. L., \& Gerwien, D. P. (2009). Teaching and learning in the social context: A meta-analysis of service learning's effects on academic, personal, social, and citizenship outcomes. Teaching of Psychology, 36(4),

233-245.

Dewey, J. (1939). Freedom and culture. New York, NY: G.P. Putnam's Sons.

Einfeld, A., \& Collins, D. (2008). The relationships between service-learning, social justice, multicultural competence,

and civic engagement. Journal of College Student Development, 49(2), 95-109.

Eyler, J., Giles, D. E., \& Braxton, J. (1997). The impact of service-learning on college students. Michigan Journal of

Community Service Learning, 4(1), 5-15.

Freire, P. (1970). Pedagogy of the oppressed. New York, NY: Herder and Herder.

Gurin, P., Meier, E. A., Nagda, B. A., \& Gurin-Sands, C. (2013). Qualitative material supporting the practice and

theoretical frameworks for intergroup dialogue. In P. Gurin, B. A. Nagda, \& X. Zu ñ iga (Eds.), Engaging race and 
gender: Intergroup dialogue in higher education (pp. 243-280). New York, NY: Russell Sage Foundation.

Gurin, P., Nagda, B. A., \& Zu' ñ iga, X. (2013). Engaging race and gender: Intergroup dialogue in higher education. New York, NY: Russell Sage Foundation.

Gurin-Sands, C., Gurin, P., Nagda, B. R. A., \& Osuna, S. (2012). Fostering a commitment to social action: How talking, thinking, and feeling make a difference in intergroup dialogue. Equity \& Excellence in Education, 45(1), 60-79.

Hackman, H. W. (2005). Five essential components for social justice education. Equity \& Excellence in Education, 38(2), 103-109.

Higher Education Research Institute. (1994). The freshman survey. Retrieved from http://www.heri.ucla.edu/ researchersToolsCodebooks.php

Kendall, J. C. (1990). Combining service and learning. A resource book for community and public service (Vol. II). Raleigh, NC: National Society for Internships and Experiential Education.

Laird, T. F., Engberg, M. E., \& Hurtado, S. (2005). Modeling accentuation effects: Enrolling in a diversity course and the importance of social action engagement. The Journal of Higher Education, 76(4), 448-476.

Manning, N., \& Edwards, K. (2014). Does civic education for young people increase political participation? A systematic review. Educational Review, 66(1), 22-45.

Markus, G. B., Howard, J. P. F., \& King, D. C. (1993). Integrating community service and classroom instruction enhances learning: Results from an experiment. Educational Evaluation and Policy Analysis, 15, 410-419.

Mayhew, M. J., \& Fernandez, S. D. (2007). Pedagogical practices that contribute to social justice outcomes. The Review of Higher Education, 31(1), 55-80.

Monard-Weissman, K. (2003). Fostering a sense of justice through international service-learning. Academic Exchange Quarterly, 7(2), 164-169.

Nagda, B. A., Gurin, P., \& Lopez, G. E. (2003). Transformative pedagogy for democracy and social justice. Race, Ethnicity, and Education, 6(2), 165-191.

Nagda, B. A., Gurin, P., Sorensen, N., Gurin-Sands, C., \& Osuna, S. M. (2009). From separate corners to dialogue and action. Race and Social Problems, 1(1), 45-55.

Nagda, B. R. A., Kim, C. W., \& Truelove, Y. (2004). Learning about difference, learning with others, learning to transgress. Journal of Social Issues, 60(1), 195-214. 
Pedersen, P. B. (1988). Handbook for developing multicultural awareness. Alexandria, VA: American Counseling Association.

Shor, I. (1992). Empowering education: Critical teaching for social change. Chicago, IL: University of Chicago. Sleeter, C. E. (1996). Multicultural education as social activism. Albany, NY: State University of New York Press. Weber, J. E., Weber, P. S., \& Young, M. A. (2010). Measuring service learning outcomes: Test-reset reliability of four scales. Psychological Reports, 107(2), 611-616.

Zu'ñ iga, X., Lopez, G. E., \& Ford, K. A. (2012). Intergroup dialogue: Critical conversations about difference, social identities, and social justice: Guest editors' introduction. Equity \& Excellence in Education, 45(1), 1-13. 